\title{
Deep Potential Effect on Magnetism of Binary Including Spintronic Material
}

\author{
Yoshinori Tanaka ${ }^{1, * 1}$, Shoji Ishida ${ }^{2}$ and Setsuro Asano ${ }^{3, * 2}$ \\ ${ }^{1}$ The Graduate School of Science and Engineering, Kagoshima University, Kagoshima 890-0065, Japan \\ ${ }^{2}$ Department of Physics, Faculty of Science, Kagoshima University, Kagoshima 890-0065, Japan \\ ${ }^{3}$ Institute of Physics, Clooege of Arts and Sciences, University of Tokyo, Tokyo 153-0041, Japan
}

\begin{abstract}
Magnetic moments on transition elements strongly depend on their circumstances. Generally, the magnetic moments, surrounded by neighbor atoms having deep potential, seem to be enhanced. For example, the moment on $\mathrm{Iron}(\mathrm{Fe})$ is indeed enhanced in the $\mathrm{Ni}_{3} \mathrm{Fe}$ and $\mathrm{Ni}-\mathrm{Fe}$ $\mathrm{Ga}$ as shown in the previous calculation. ${ }^{1)}$ In both alloys, the nearest neighbors of Fe are Nickel (Ni) atoms, having deeper potential than Fe.

To examine the effect of surrounding deep potential, the electronic structures of binary alloys between $3 \mathrm{~d}$-transition-metal elements are calculated for the $\mathrm{B} 2$ and $\mathrm{L}_{2}$ structure. The surrounding deeper potential draw the electronic states of the subject atoms into lower energy range and bring the various moments and interesting features. In other words, the effects of surrounding potential can control energy level of $D O S$ peak or the band gap. Were the structure of $\mathrm{Cu}_{3} \mathrm{~V}$ to be the $\mathrm{L}_{2}$, the magnetic moment on $\mathrm{V}$ would become unusually large $\left(1.99 \mu_{\mathrm{B}}\right)$. Some alloys calculated show the high spin polarization at the Fermi level $\left(E_{\mathrm{F}}\right)$. The values of the spin polarization at the $E_{\mathrm{F}}$ evaluated from the density of states $(D O S)$ for $\mathrm{Ni}_{3} \mathrm{Cr}, \mathrm{Ni}_{3} \mathrm{Co}$ and $\mathrm{CoFe}$ are $0.94,-0.86$ and -0.88 respectively. To control the energy level of DOS peak or the band gap would give us another means for finding new spintronic materials. The relations between whole magnetic moment and the valence electron concentration show the Slater-Pauling like behavior.
\end{abstract}

(Received October 29, 2004; Accepted January 13, 2005)

Keywords: electronic structure, magnetic moment, $\mathrm{L1}_{2}, \mathrm{Ni}_{3} \mathrm{Co}, \mathrm{Ni}_{3} \mathrm{Cr}$, spintronic

\section{Introduction}

The enhancement of magnetic moments on Iron $(\mathrm{Fe})$ in compounds and alloys has been actively discussed as in the $\mathrm{Fe}_{16} \mathrm{~N}_{2}$. In the previous calculations, the large $\mathrm{Fe}$ moments were estimated in the $\mathrm{Ni}-\mathrm{Fe}-\mathrm{Ga}$ and $\mathrm{Ni}_{3} \mathrm{Fe} .{ }^{1)}$ The nearest neighbor atoms of $\mathrm{Fe}$ are eight $\mathrm{Nickel}(\mathrm{Ni})$ atoms in the Ni$\mathrm{Fe}-\mathrm{Ga}$ with the $\mathrm{L} 2{ }_{1}$ structure (full-Heusler) and twelve $\mathrm{Ni}$ atoms in the $\mathrm{Ni}_{3} \mathrm{Fe}$ with the $\mathrm{L}_{2}$ structure. It was also reported that the moment on Fe surrounded by Co was also enhanced in the Co-Fe-Al with the $\mathrm{L} 2{ }_{1}$ structure. ${ }^{2)}$ The results suggest that there are two factors to enhance Fe moment: the enlargement of interatomic distances caused by Gallium (Ga) and the surrounding deep potential made by $\mathrm{Ni}$. We pay attention to the latter factor.

In this paper, we consider the deep potential effect on the 3d-transition-metal elements ( $\mathrm{V}, \mathrm{Cr}, \mathrm{Mn}, \mathrm{Fe}, \mathrm{Co})$ in the two kinds of circumstances. The circumstances are assumed in the $\mathrm{B} 2$ structure as a bcc-type and the $\mathrm{L}_{2}$ structure as an fcctype which are shown in Fig. 1. The surrounding neighbor elements are chosen among the 3d-transition-metal elements ( $\mathrm{Fe}, \mathrm{Co}, \mathrm{Ni}, \mathrm{Cu}$ ) to have the larger atomic number than the subject element. These circumstances are not meet all the real phase for the subject elements. Some alloys actually exist as ordered in such structures but some do not.

As shown in the previous work, ${ }^{1)}$ the local density of states $(D O S)$ of $\mathrm{Fe}$ in the $\mathrm{Ni}_{3} \mathrm{Fe}$ with the $\mathrm{L}_{2}$ structure have peculiar feature. The majority-spin DOS scarcely exist over the $E_{\mathrm{F}}$ and very high peak of minority-spin DOS exist just above the $E_{\mathrm{F}}$. If one can move this high peak to just on the $E_{\mathrm{F}}$, the spin polarization at the $E_{\mathrm{F}}$ of the alloy becomes high: one can get a candidate of a spintronic material.

\footnotetext{
${ }^{* 1}$ Graduate Student, Kagoshima University

*2National Center for University Entrance Examinations, Tokyo 153-8501, Japan
}

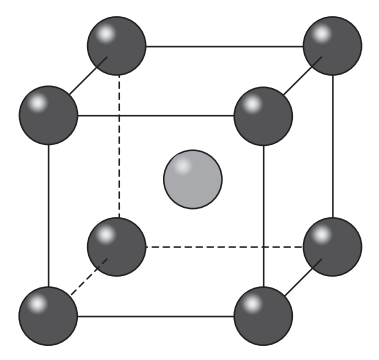

nearest neighbor : 8

B2: CsCl-type

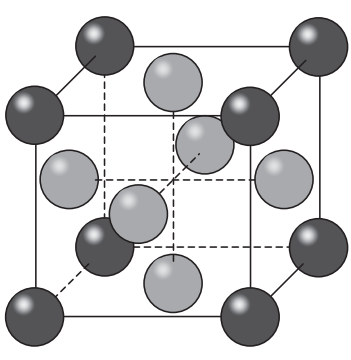

nearest neighbor : 12

$\mathrm{L1}_{2}: \mathrm{Cu}_{3} \mathrm{Au}$-type
Fig. 1 The crystal structures of the $\mathrm{B} 2$ and $\mathrm{L}_{2}$ structures. The electronic structures of the subject atoms (V, Cr, Mn, Fe and Co) are calculated for these two types of the structures.

\section{Crystal Structure and Method of Calculation}

To clarify the effect of circumstances on the electronic structure, we choose typical distinctive two structures, the B2 (CsCl-type) and $\mathrm{L}_{2}\left(\mathrm{Cu}_{3} \mathrm{Au}\right.$-type) structures. Both of the structures have the same symmetry as the pm $\overline{3} \mathrm{~m}$, the $221 \mathrm{st}$ space group symmetry in the 'International Tables for Crystallography'. ${ }^{3)}$ The unit cells of both structures are shown in Fig. 1. The numbers of the nearest neighbor atoms are eight in the $\mathrm{B} 2$ structure and twelve in the $\mathrm{L}_{2}$ structure. The $\mathrm{L}_{2}$ structure is one of the close-packed structures.

Band calculations are carried out self consistently by the LMTO-ASA method. ${ }^{4)}$ The exchange correlation potential is treated within the framework of the local-spin-density (LSD) approximation. ${ }^{5)}$ To find the reasonable equilibrium lattice constants, the lattice constant dependence of the total energy is calculated and determined the theoretical lattice constant and the ratio of the atomic spheres. The radii of the atomic spheres of $\mathrm{V}\left(\mathrm{r}_{\mathrm{V}}\right), \mathrm{Cr}\left(\mathrm{r}_{\mathrm{Cr}}\right), \mathrm{Mn}\left(\mathrm{r}_{\mathrm{Mn}}\right), \mathrm{Fe}\left(\mathrm{r}_{\mathrm{Fe}}\right), \mathrm{Co}\left(\mathrm{r}_{\mathrm{Co}}\right), \mathrm{Ni}$ 
Table 1 Theoretical lattice constants of the $\mathrm{B} 2$ and $\mathrm{L}_{2}$ structures.

\begin{tabular}{llccccc}
\hline & & \multicolumn{5}{c}{ Lattice constant, $\mathrm{nm}$} \\
\hline $\mathrm{X}:$ & & $\mathrm{V}$ & $\mathrm{Cr}$ & $\mathrm{Mn}$ & $\mathrm{Fe}$ & $\mathrm{Co}$ \\
\hline $\mathrm{B} 2$ & $\mathrm{Fe}-\mathrm{X}$ & 0.288 & 0.283 & 0.281 & 0.282 & \\
& $\mathrm{Co}-\mathrm{X}$ & 0.288 & 0.286 & 0.284 & 0.283 & 0.279 \\
& $\mathrm{Ni}-\mathrm{X}$ & 0.291 & 0.286 & 0.289 & 0.283 & 0.277 \\
& $\mathrm{Cu}-\mathrm{X}$ & 0.294 & 0.287 & 0.293 & 0.285 & 0.280 \\
\hline $\mathrm{L1}_{2}$ & $\mathrm{Fe}_{3}-\mathrm{X}$ & 0.356 & 0.352 & 0.354 & 0.346 & \\
& $\mathrm{Co}_{3}-\mathrm{X}$ & 0.354 & 0.351 & 0.348 & 0.353 & 0.352 \\
& $\mathrm{Ni}_{3}-\mathrm{X}$ & 0.357 & 0.355 & 0.355 & 0.354 & 0.351 \\
& $\mathrm{Cu}_{3}-\mathrm{X}$ & 0.368 & 0.367 & 0.365 & 0.360 & 0.357 \\
\hline
\end{tabular}

$\left(\mathrm{r}_{\mathrm{Ni}}\right)$ and $\mathrm{Cu}\left(\mathrm{r}_{\mathrm{Cu}}\right)$ are used in the same ratio for both of the structures. In any alloys, the charge neutrality in the spheres is fulfilled. The ratio of the radii is $\mathrm{r}_{\mathrm{V}}: \mathrm{r}_{\mathrm{Cr}}: \mathrm{r}_{\mathrm{Mn}}: \mathrm{r}_{\mathrm{Fe}}: \mathrm{r}_{\mathrm{Co}}$ : $\mathrm{r}_{\mathrm{Ni}}: \mathrm{r}_{\mathrm{Cu}}=1.102: 1.080: 1.068: 1.044: 1.022: 1.000: 0.999$.

\section{Results}

\subsection{Total energy}

To determine the lattice constants theoretically, the total energies are calculated as a function of the lattice constants. The minimum value of the total energy gives the theoretical value of the lattice constant. The theoretical lattice constants taken in this calculation are summarized in Table 1. In our method, the theoretical lattice constant for ordered intermetallic compound sufficiently coincide with the experimental ones, especially for close-packed structures. For instance, the experimental lattice constant of $\mathrm{Ni}_{3} \mathrm{Fe}$ is $0.3545 \mathrm{~nm} .{ }^{6)}$ In this paper, we will discuss the electronic structures calculated at the theoretical lattice constants. However, some alloys does not have ordered phase as the $\mathrm{B} 2$ or $\mathrm{L}_{2}$ structure so that these structures for such alloys are virtual.

\subsection{Magnetic moments}

Among pure transition metals, Iron is a ferromagnet and Manganese is a complicated antiferromagnet in the bcc structure, while Cobalt and Nickel are ferromagnets in the fcc structure. Here, we examine the change of the magnetic properties of the $3 \mathrm{~d}$-transition-metal elements in the bcc and fcc circumstances, where the surrounding potential is deeper than the self potential. The surrounding potential made by neighbors becomes deeper in the order of $\mathrm{Fe}, \mathrm{Co}, \mathrm{Ni}$ and $\mathrm{Cu}$.

The magnetic moments due to the spin polarization are estimated in both structures. The total magnetic moments of alloys can be understood as a function of valence electron concentration. The relation between the whole magnetic moments and the valence electron concentration is given in Fig. 2. The relations between them show the Slater-Pauling like behavior.

The values of the magnetic moments on the subject elements ( $\mathrm{V}, \mathrm{Cr}, \mathrm{Mn}, \mathrm{Fe}$ and $\mathrm{Co}$ ) in the $\mathrm{B} 2$ and $\mathrm{L} 1_{2}$ structures are listed in Table 2. Paying attention to pure Iron (Fe), the magnetic moment is $2.2 \mu_{\mathrm{B}}$ in the bcc structure and $0.15 \mu_{\mathrm{B}}$ in the fcc structure. In the both circumstances, the Fe moment is enhanced where the surrounding potential becomes deeper. Especially, when the surrounding element changes from Fe to $\mathrm{Co}$, the increase is very large in the fcc circumstances.

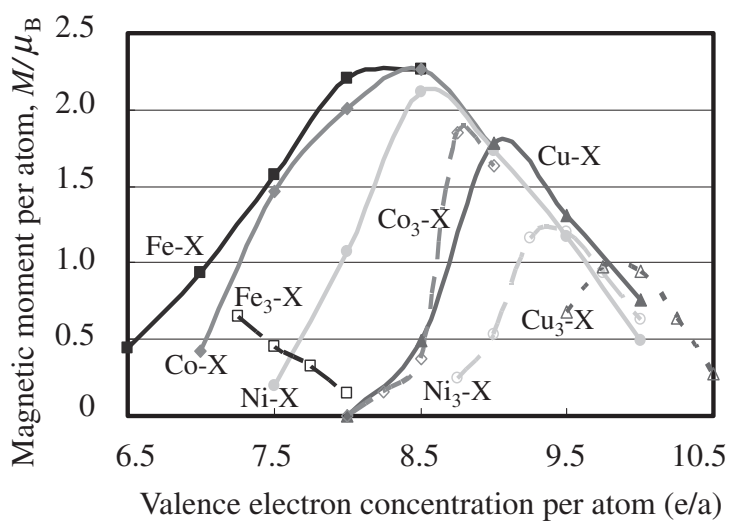

Fig. 2 The relation between the total magnetic moment and valence electron concentration.

Table 2 Magnetic moments on $\mathrm{X}(\mathrm{X}=\mathrm{V}, \mathrm{Cr}, \mathrm{Mn}, \mathrm{Fe}$ and $\mathrm{Co})$ in the B2 and $\mathrm{L}_{2}$ structures.

\begin{tabular}{clccccc}
\hline & & \multicolumn{6}{c}{ Moment on X, $\mu_{\mathrm{B}}$} \\
\hline $\mathrm{X}$ & & $\mathrm{V}$ & $\mathrm{Cr}$ & $\mathrm{Mn}$ & $\mathrm{Fe}$ & $\mathrm{Co}$ \\
\hline $\mathrm{B} 2$ & $\mathrm{Fe}-\mathrm{X}$ & -0.30 & 0.33 & 1.22 & 2.20 & \\
& $\mathrm{Co}-\mathrm{X}$ & 0.26 & 1.53 & 2.68 & 2.73 & 1.76 \\
& $\mathrm{Ni}-\mathrm{X}$ & 0.28 & 1.74 & 3.42 & 2.77 & 1.71 \\
& $\mathrm{Cu}-\mathrm{X}$ & - & 0.97 & 3.43 & 2.55 & 1.46 \\
\hline $\mathrm{L1}_{2}$ & $\mathrm{Fe}_{3}-\mathrm{X}$ & -0.58 & -0.92 & -2.22 & 0.15 & \\
& $\mathrm{Co}_{3}-\mathrm{X}$ & - & -1.12 & 2.04 & 2.53 & 1.63 \\
& $\mathrm{Ni}_{3}-\mathrm{X}$ & 0.73 & 1.95 & 3.01 & 2.85 & 1.70 \\
& $\mathrm{Cu}_{3}-\mathrm{X}$ & 1.99 & 3.27 & 3.52 & 2.56 & 1.22 \\
\hline
\end{tabular}

Roughly speaking, the magnitude of the magnetic moment increases as the surrounding potential becomes deeper. Moreover, the marvelous result is seen in the $\mathrm{V}$ moments. Although $\mathrm{Cu}$ and $\mathrm{V}$ are immiscible, the magnetic moment on $\mathrm{V}$ in case where $\mathrm{V}$ is surrounded by $\mathrm{Cu}$ in ordered $\mathrm{Cu}_{3} \mathrm{~V}$ with the $\mathrm{L}_{2}$ structure would have an unusual value $\left(1.99 \mu_{\mathrm{B}}\right)$. On the other hand, not every value of the magnetic moment on the subject atoms is enhanced. The magnetic moments on $\mathrm{X}$ ( $=\mathrm{Cr}$ and $\mathrm{Mn}$ ) in the $\mathrm{Fe}_{3} \mathrm{X}$ and $\mathrm{Co}_{3} \mathrm{X}$ are antiparallel to that on the neighbor $\mathrm{Fe}$ and $\mathrm{Co}$.

These features described above are reflected in the densities of states (DOS). They are explained in terms of the changes of DOS shape caused by the difference of the crystal structures and the surrounding potential, in the next section.

\subsection{Density of state \\ 3.3.1 Magnetic property}

To understand the various magnetic moments of the subject atoms, it is significant to examine the effect of neighbor atoms. The densities of states (DOS) help us to understand the effect of surrounding neighbors.

At first, we pay attention to the large $\mathrm{V}$ moments in the $\mathrm{Cu}_{3} \mathrm{~V}$ with the $\mathrm{L}_{2}$ structure. This phase is not likely to exist because $\mathrm{Cu}$ and $\mathrm{V}$ are immiscible, and Y. X. Shen et al. conclude in their calculation report that the $\mathrm{L}_{2}$ structure is not stable as $\mathrm{Cu}-\mathrm{V}$ ordered phase. ${ }^{7}$ Whether the $\mathrm{Cu}_{3} \mathrm{~V}$ with the $\mathrm{L}_{2}$ structure exist or not, the large magnetic moment in 


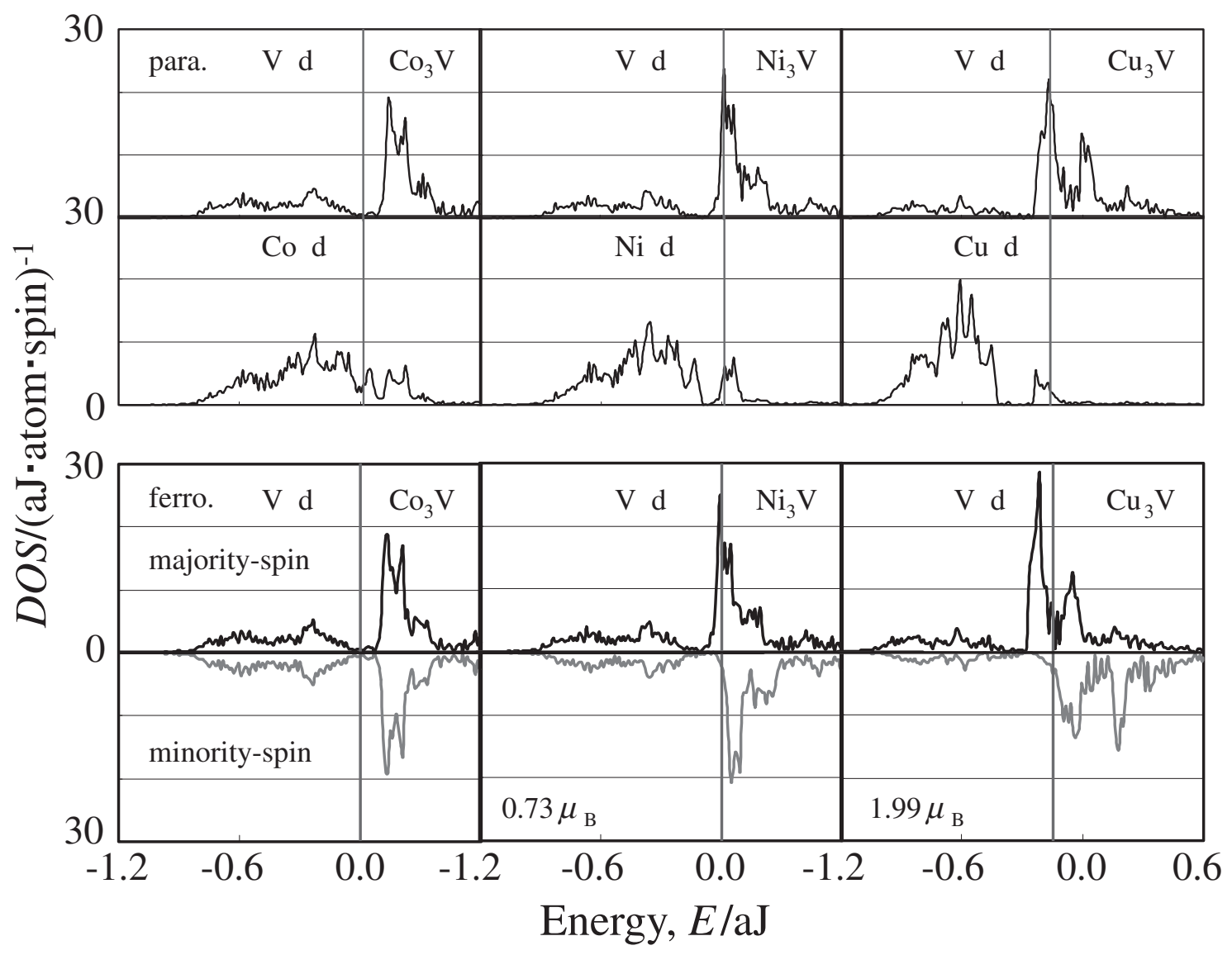

Fig. 3 The paramagnetic local DOS of $\mathrm{V}$ and their neighbor atoms (above) and ferromagnetic $D O S$ of $\mathrm{V}$ (below) in $\mathrm{Co}_{3} \mathrm{~V}, \mathrm{Ni}_{3} \mathrm{~V}$ and $\mathrm{Cu}_{3} \mathrm{~V}$. The vertical line shows the $E_{\mathrm{F}}$.

this circumstances suggest significant thing. The paramagnetic local DOS of $\mathrm{V}$ and their neighbors $(\mathrm{Co}, \mathrm{Ni}$ and $\mathrm{Cu})$ in the $\mathrm{L}_{2}$ structure are shown in the upper part of Fig. 3. When the neighbors change from $\mathrm{Co}$ to $\mathrm{Cu}$, the electronic states of $\mathrm{V}$ move to the low energy range as the result of the d-states hybridization with the neighbors. In other words, as the surrounding potential become deeper, the DOS of $\mathrm{V}$ move to the lower energy range. Then, the high peak of DOS of $\mathrm{V}$ are situated at the $E_{\mathrm{F}}$ in the $\mathrm{Ni}_{3} \mathrm{~V}$ and $\mathrm{Cu}_{3} \mathrm{~V}$. The $D O S$ of $\mathrm{V}$ in these alloys satisfies the Stoner condition for the occurrence of ferromagnetism. The lower part of Fig. 3 shows the ferromagnetic DOS of $\mathrm{V}$ in the $\mathrm{Co}_{3} \mathrm{~V}, \mathrm{Ni}_{3} \mathrm{~V}$ and $\mathrm{Cu}_{3} \mathrm{~V}$. The same tendency can be seen as the deep potential effect on the paramagnetic DOS of subject atoms. As the surrounding potential become deeper, the DOS of the subject atoms move to the lower energy range, and then we can guess the magnetic property of the subject atoms from the DOS near the $E_{\mathrm{F}}$. In the virtual alloys of $\mathrm{Cu}_{3} \mathrm{~V}$ with the $\mathrm{L1}_{2}$ structure, the effect on $\mathrm{V}$ cause an unusual large magnetic moment $\left(1.99 \mu_{\mathrm{B}}\right)$.

In Fig. 4, the paramagnetic DOS of Fe are shown for the bcc and the fcc structure. The $E_{\mathrm{F}}$ is situated at the high peak of the DOS in the bcc structure, while the value of the DOS at the $E_{\mathrm{F}}$ are not so large in the fcc structure. This is reflected in the magnetic moments on $\mathrm{Fe}$ in the $\mathrm{B} 2$ and $\mathrm{L}_{2}$ structures described in the previous section. When the neighbors change from $\mathrm{Fe}$ to $\mathrm{Cu}$ in the $\mathrm{L}_{2}$ structure, the DOS of the subject atoms move to the lower energy range and the DOS near the

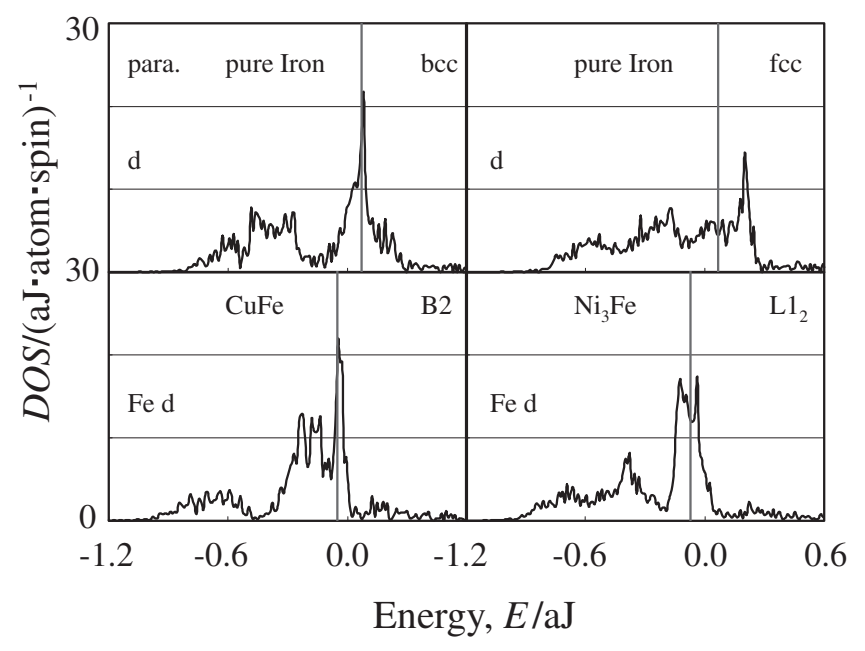

Fig. 4 The paramagnetic local DOS of Fe in pure Iron with the bcc and the fcc structure, and in the CuFe with the $\mathrm{B} 2$ structure and in the $\mathrm{Ni}_{3} \mathrm{Fe}$ with $\mathrm{L1}_{2}$ structure. The vertical line shows the $E_{\mathrm{F}}$.

$E_{\mathrm{F}}$ become higher and form a peak. The same tendency is seen in the B2 structure. The features are seen in Fig. 4. Thus, Fe surrounded by deeper potential than self-potential becomes easy to carry a large magnetic moment.

The total DOS of the $\mathrm{Fe}_{3} \mathrm{Cr}$ are shown in Fig. 5, where the $E_{\mathrm{F}}$ is situated in the large valley. This suggests that the $\mathrm{Fe}_{3} \mathrm{Cr}$ exhibits antiferromagnetism as pure $\mathrm{Cr}$ which is antiferro- 


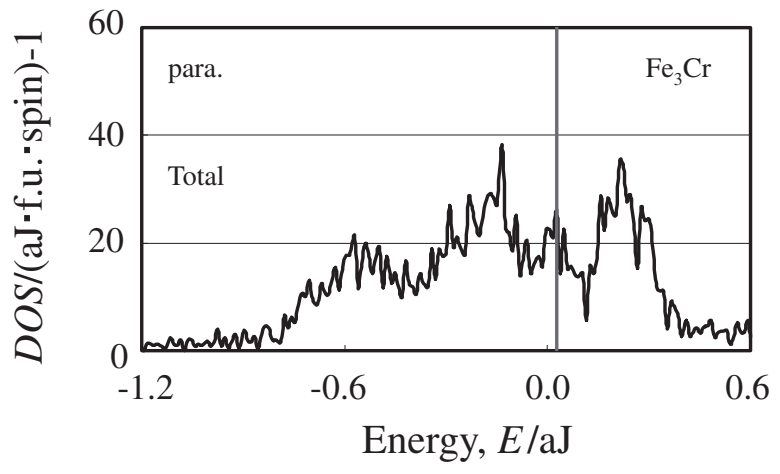

Fig. 5 The paramagnetic total $\mathrm{DOS}$ of the $\mathrm{Fe}_{3} \mathrm{Cr}$. The vertical line shows the $E_{\mathrm{F}}$.

magnetic and the $E_{\mathrm{F}}$ is situated in the large valley of the DOS. The moment on $\mathrm{Cr}$ in the $\mathrm{Fe}_{3} \mathrm{Cr}$ is really antiparallel to that on the neighbor $\mathrm{Fe}$. The $E_{\mathrm{F}}$ in the $\mathrm{Fe}_{3} \mathrm{X}$ and the $\mathrm{Co}_{3} \mathrm{X}$ $(\mathrm{X}=\mathrm{Cr}$ and $\mathrm{Mn})$ is also situated in the large valley of the total DOS. Therefore, we can guess that the moments on $\mathrm{X}$ $\left(=\mathrm{Cr}\right.$ and $\mathrm{Mn}$ ) in the $\mathrm{Fe}_{3} \mathrm{X}$ and $\mathrm{Co}_{3} \mathrm{X}$ are antiparallel to those on the neighbors.

In the same way, the surrounding deep potential affects the overall subject atoms ( $\mathrm{V}, \mathrm{Cr}, \mathrm{Mn}, \mathrm{Fe}, \mathrm{Co})$. Namely, as the surrounding potential become deeper, the majority-spin DOS of the subject elements are drawn into the lower energy range. Then the DOS of the subject elements at the $E_{\mathrm{F}}$ change and the result cause the changes of magnetic property.

\subsubsection{Spintronic material}

Paying attention to the $D O S$ at the $E_{\mathrm{F}}$, we notice that there are some alloys with characteristic property. The high spin polarization at the $E_{\mathrm{F}}$ cause spin dependent conduction and that conduction is useful for a GMR (giant magnetoresistance), TMR (tunneling magnetoresistance) or MRAM (magnetic random access memory) application. Hereafter, we turn our eyes to the candidates for such spintronic materials. The spin polarization $P$ at the $E_{\mathrm{F}}$ is defined as

$$
P=\frac{D_{\text {major. }}-D_{\text {minor. }}}{D_{\text {major. }}+D_{\text {minor. }}}
$$

where $D_{\sigma}$ ( $\sigma=$ major., minor.) is the density of states at the $E_{\mathrm{F}}$ with spin $\sigma$ (majority, minority). The spin polarizations at the $E_{\mathrm{F}}$ of the candidates are listed in Table 3.

In our calculation, the CoMn in the B2 structure shows the high spin polarization at the $E_{\mathrm{F}}(0.92)$. Even if the B2 structure of CoMn is not reported experimentally, this calculated result suggests the characteristics of the DOS to be the high spin polarization in bcc circumstances. Figure 6 shows the DOS of the CoMn. The local DOS of $\mathrm{Mn}$ and Co have two peaks, which are characteristics for the bcc $3 \mathrm{~d}$ -

Table 3 Spin polarization at the Fermi level.

\begin{tabular}{ccccc}
\hline \multicolumn{5}{c}{ Spin polarization } \\
\hline $\mathrm{L}_{2}{ }_{2}$ & $\mathrm{Ni}_{3} \mathrm{Cr}$ & $\mathrm{Ni}_{3} \mathrm{Fe}$ & $\mathrm{Ni}_{3} \mathrm{Co}$ & $\mathrm{Cu}_{3} \mathrm{Fe}$ \\
$P$ & 0.94 & -0.66 & -0.86 & -0.80 \\
\hline $\mathrm{B} 2$ & $\mathrm{FeCr}$ & $\mathrm{CoCr}$ & $\mathrm{CoMn}$ & $\mathrm{CoFe}$ \\
$P$ & 0.79 & 0.56 & 0.92 & -0.88 \\
\hline
\end{tabular}
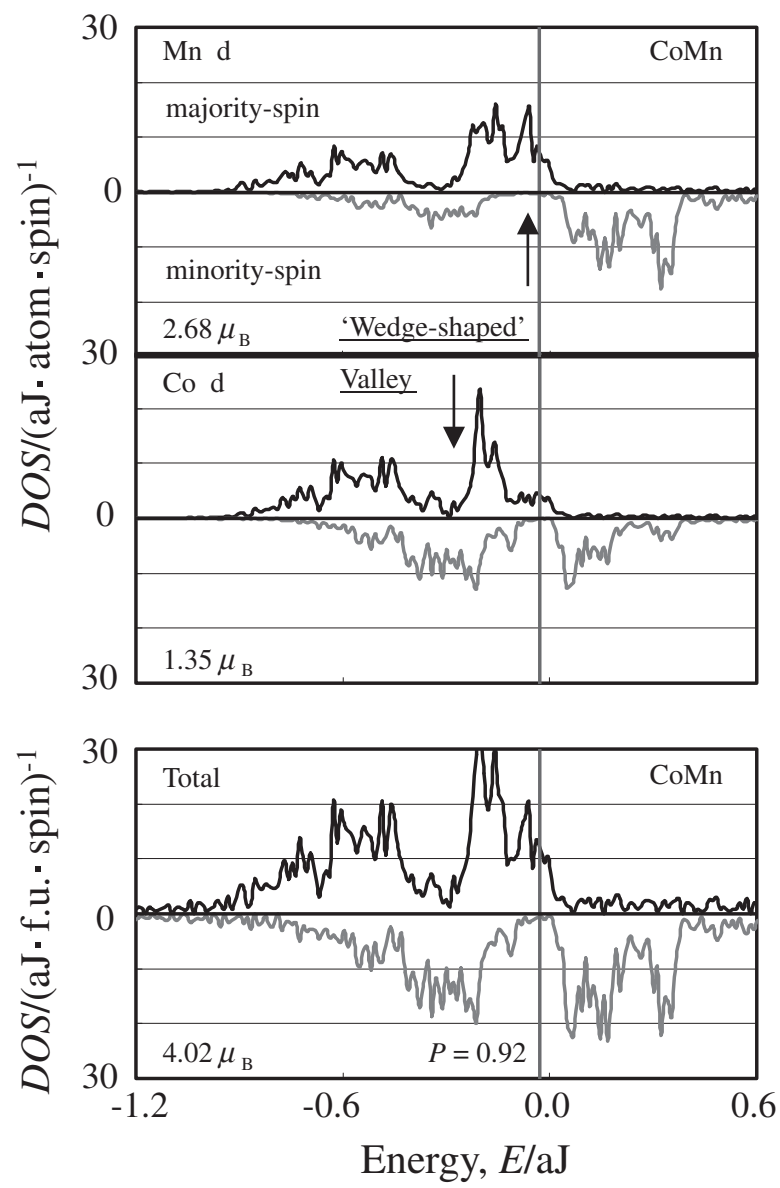

Fig. 6 The local DOS of Mn and its neighbor Co in CoMn (above), and the total DOS of CoMn (below). The vertical line shows the $E_{\mathrm{F}}$.

transition metals. When the $E_{\mathrm{F}}$ exists at the 'wedge-shaped' valley in the minority-spin state, the alloys show the high spin polarization at the $E_{\mathrm{F}}$. This situation is similar to those of the bcc pure Iron $(\mathrm{Fe})$ that $P$ calculated is 0.55 . If the $E_{\mathrm{F}}$ locates in the 'wedge-shaped' valley in the minority spin state, the alloys in the bcc circumstances will be the candidates as the high spin polarization alloy.

Next, we turn our attention to the $\mathrm{Ni}_{3} \mathrm{X}(\mathrm{X}=\mathrm{Cr}, \mathrm{Mn}, \mathrm{Fe}$ and $\mathrm{Co}$ ) with the $\mathrm{L}_{2}$ structure. The probability of existence of these alloys seems to be high, so that the grand state of pure $\mathrm{Ni}$ is in the fcc structure. In fact, for instances, the $\mathrm{L1}_{2}$ ordered phase of the $\mathrm{Ni}_{3} \mathrm{Cr}$ and $\mathrm{Ni}_{3} \mathrm{Fe}$ is reported. ${ }^{8,9)}$ The local DOS of the $\mathrm{X}$ atoms are shown in Fig. 7. The peak move to the lower energy range as the $\mathrm{X}$ changes $\mathrm{Cr}$ to $\mathrm{Co}$, and are mostly occupied for $\mathrm{X}=\mathrm{Fe}$ and Co. The high peak of $D O S$ is situated at the $E_{\mathrm{F}}$ in the majority-spin for $\mathrm{X}=\mathrm{Cr}$ while in the minority-spin for $\mathrm{X}=\mathrm{Co}$.

The local DOS of the neighbor Ni are shown in Fig. 8. The DOS shape of $\mathrm{Ni}$ in the $\mathrm{Ni}_{3} \mathrm{Co}$ is similar to that of $\mathrm{Ni}$ with the fcc structure, Generally, the DOS of typical fcc transition metals show no large valley. However, the Ni DOS of minority-spin in the $\mathrm{Ni}_{3} \mathrm{Cr}$ or $\mathrm{Ni}_{3} \mathrm{Mn}$ have a valley: the band gap of d-states in minority-spin clearly exists near the $E_{\mathrm{F}}$. As the subject atoms change from $\mathrm{Co}$ to $\mathrm{Cr}$, the $D O S$ of Ni move to the higher energy range. We consider this the result of the hybridization between the d-states of $\mathrm{Ni}$ and the subject elements. The shallow potential effect of the subject elements 


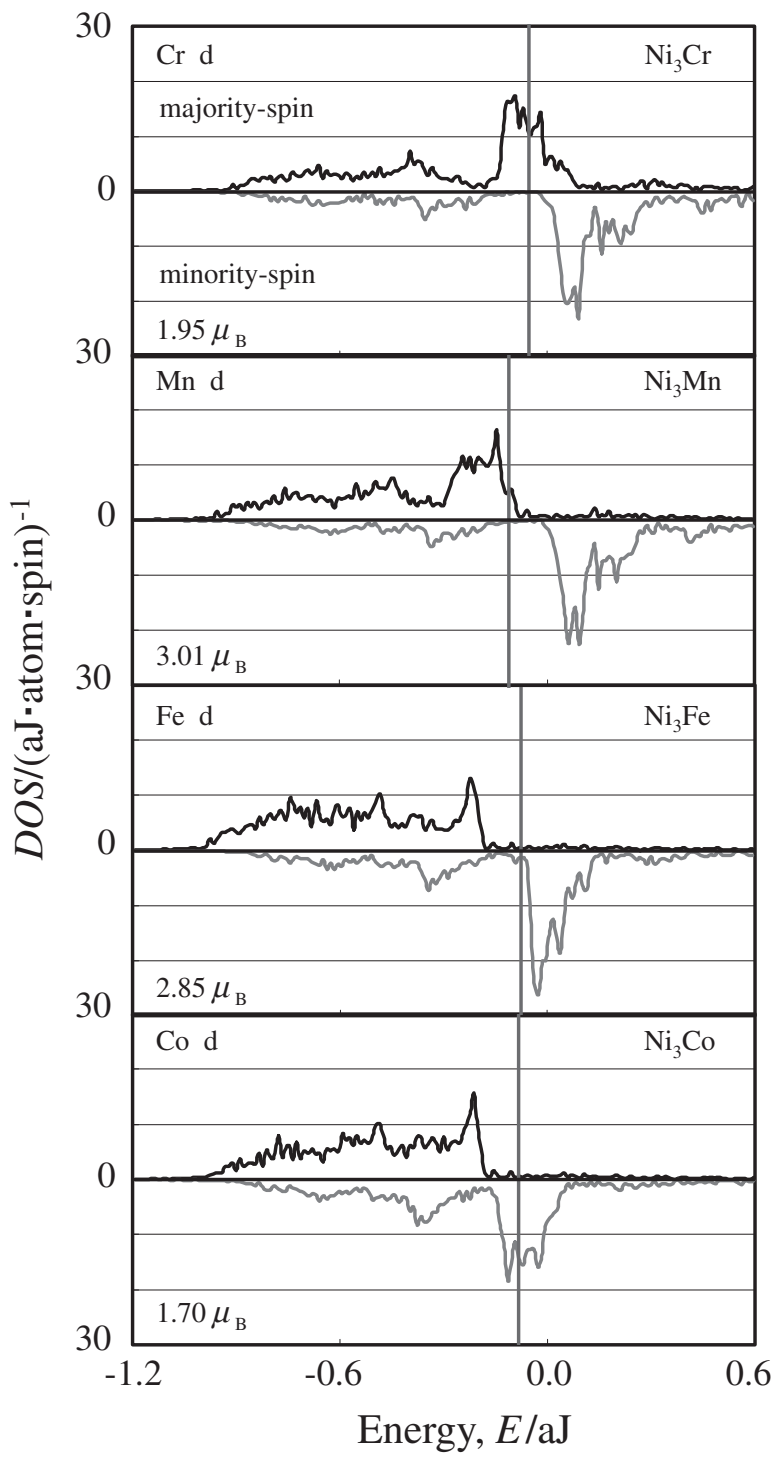

Fig. 7 The local DOS of $\mathrm{X}(\mathrm{X}=\mathrm{Cr}, \mathrm{Mn}, \mathrm{Fe}$ and $\mathrm{Co})$ in $\mathrm{Ni}_{3} \mathrm{X}$. The vertical line shows the $E_{\mathrm{F}}$.

on $\mathrm{Ni}$ can be seen.

The total DOS of this series are shown in Fig. 9, which reflect the characteristics of the DOS of $\mathrm{Ni}$ and $\mathrm{X}$ atoms described previously. Although $\mathrm{Ni}_{3} \mathrm{Cr}$ is not a half-metallic alloy, the electronic structure of this alloy shows the halfmetallic-type high spin-polarization at the $E_{\mathrm{F}}$. The $D O S$ of the $\mathrm{Ni}_{3} \mathrm{Co}$ and $\mathrm{Ni}_{3} \mathrm{Cr}$ show the high spin-polarization at the $E_{\mathrm{F}}$. The $\mathrm{Ni}_{3} \mathrm{Co}$ is categorized as a typical strong ferromagnetic-type high spin polarization alloy, in which the majorityspin states are mostly occupied. This type strong ferromagnetic-type high spin polarization alloy seen in the B2 structure is CoFe that $P$ calculated is -0.88 .

\section{Discussion}

In the previous work, ${ }^{1)}$ we notice the peculiar features of the local DOS for $\mathrm{Fe}$ in the $\mathrm{Ni}_{3} \mathrm{Fe}$ with the $\mathrm{L}_{2}$ structure. The majority-spin $D O S$ scarcely exist over the $E_{\mathrm{F}}$ and very high peak of minority-spin $D O S$ exist just above the $E_{\mathrm{F}}$ shown in Fig. 7. To move the peak to just on the $E_{\mathrm{F}}$, we can use the

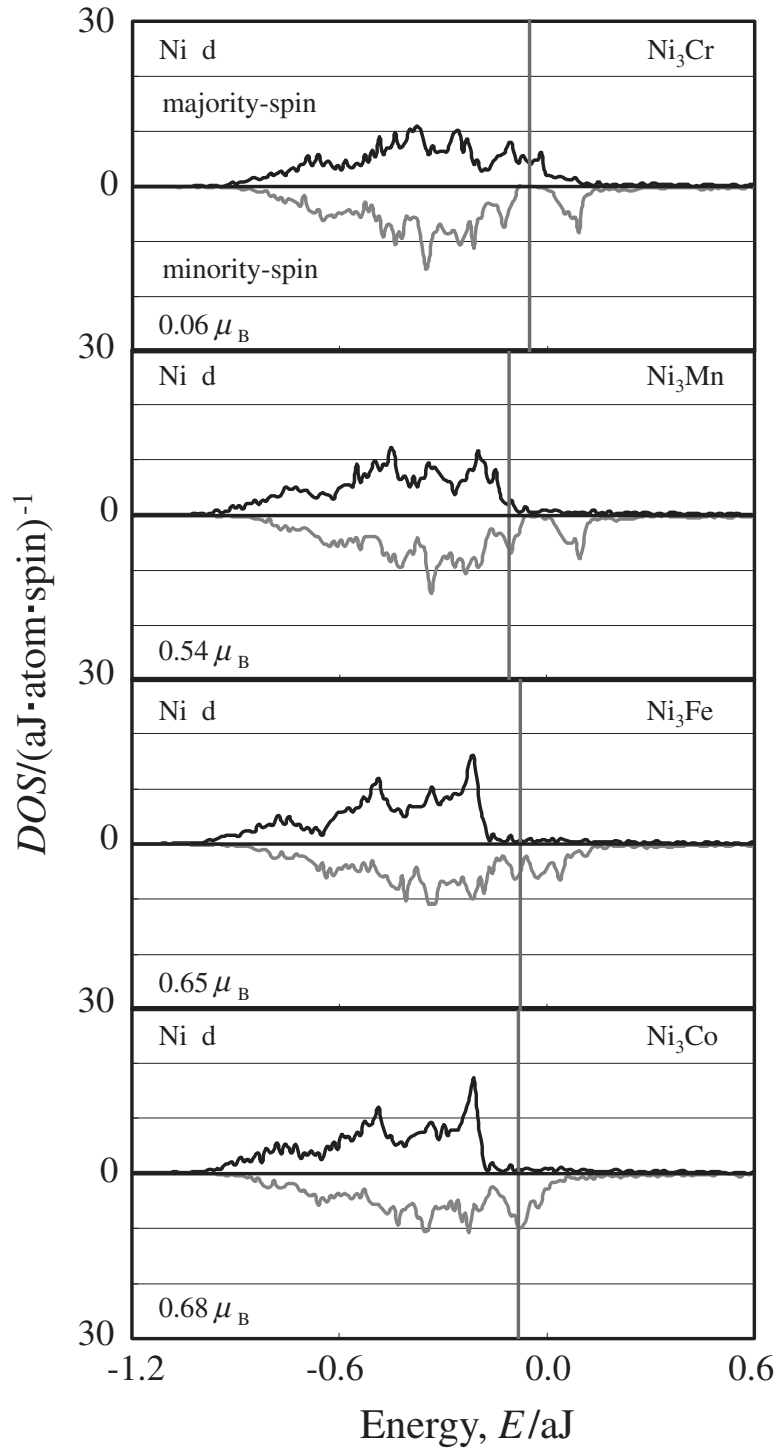

Fig. 8 The local DOS of $\mathrm{Ni}$ in $\mathrm{Ni}_{3} \mathrm{X}(\mathrm{X}=\mathrm{Cr}, \mathrm{Mn}, \mathrm{Fe}$ and $\mathrm{Co})$. The vertical line shows the $E_{\mathrm{F}}$.

deep potential effect. Figure 10 shows the local and total $D O S$ of $\mathrm{Cu}_{3} \mathrm{Fe}$. As the effect of the deep potential of $\mathrm{Cu}$, the majority-spin local DOS of $\mathrm{Fe}$ in the $\mathrm{Cu}_{3} \mathrm{Fe}$ move to the lower energy range and the high peak of the minority-spin locates at the $E_{\mathrm{F}}$. On the other hand, in the minority-spin states, the states in the lower energy range decrease and form the high peak near the $E_{\mathrm{F}}$ as the consequence of the d-d exchange interaction. This result suggests that to change the surrounding potential lead some candidates to suitable for spintronic materials.

\section{Conclusion}

The electronic structures of binary alloys were calculated for the $\mathrm{B} 2$ and the $\mathrm{L}_{2}$ structures to make clear the surrounding deep potential effect on magnetic property. The magnetic moments on the subject elements (V, Cr, Mn, $\mathrm{Fe}$ and $\mathrm{Co}$ ) are strongly affected by the surrounding potential. As the surrounding potential becomes deeper, the DOS of the subject atoms move to the lower energy range. Roughly 


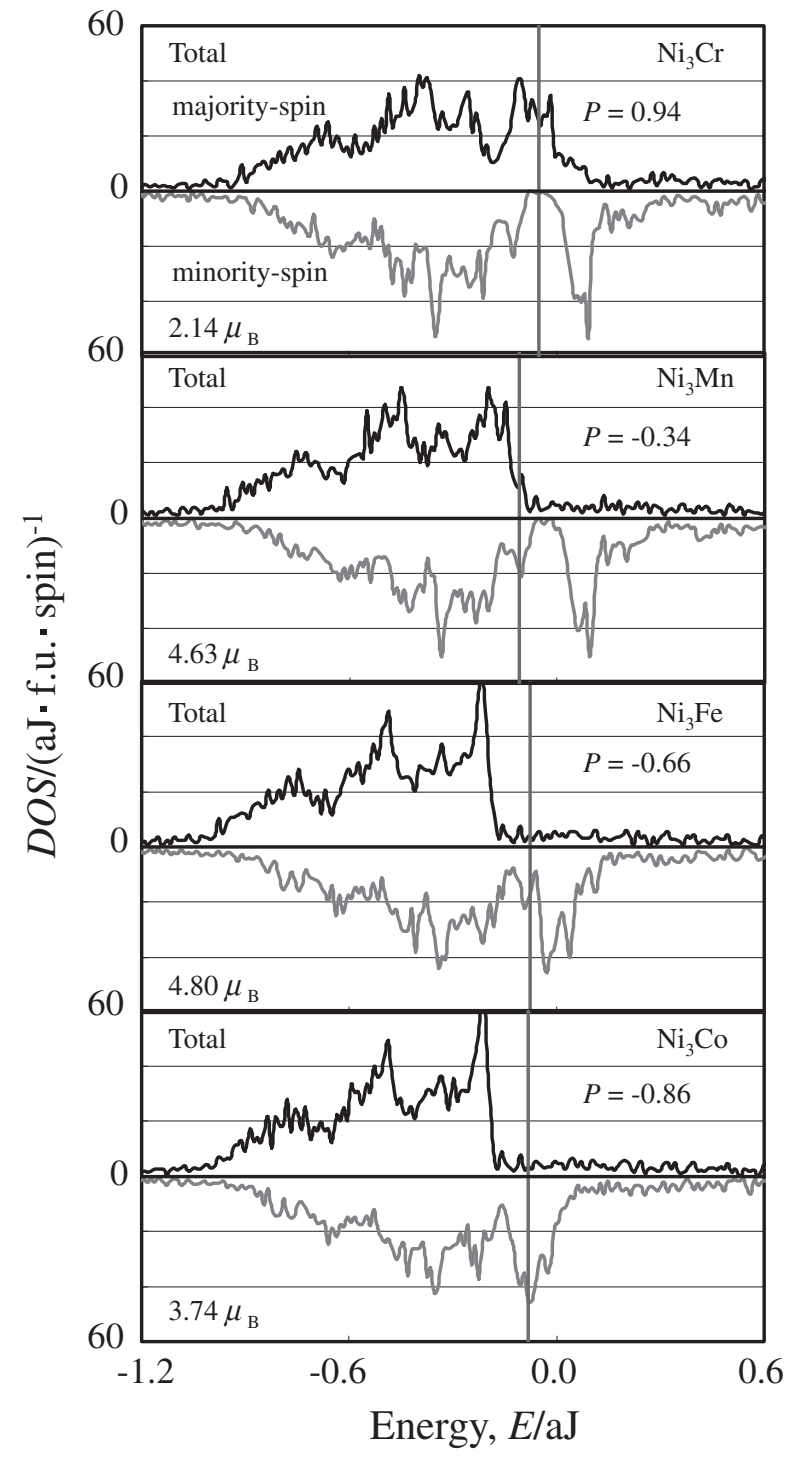

Fig. 9 The total $D O S$ of $\mathrm{Ni}_{3} \mathrm{X}(\mathrm{X}=\mathrm{Cr}, \mathrm{Mn}, \mathrm{Fe}$ and $\mathrm{Co})$. The vertical line shows the $E_{\mathrm{F}}$.

speaking, the effect brings the enhancement of the magnetic moment of the subject elements. The relation between the whole magnetic moments and valence electron concentrations show the Slater-Pauling like behavior.

Some alloys show the high spin-polarization at the $E_{\mathrm{F}}$. The high spin polarization alloys are categorized in two types: the halfmetallic-type and the strong ferromagnetic-type. In the $\mathrm{L1}_{2}$ structure, the $\mathrm{Ni}_{3} \mathrm{Cr}$ shows the halfmetallic-type and the $\mathrm{Ni}_{3} \mathrm{Co}$ shows the strong ferromagnetic-type. In the B2 structure, the high spin polarization of CoMn suggests a necessary condition for high spin-polarization in bcc circumstances. This condition is common with those of Heusler alloys. When the $E_{\mathrm{F}}$ exists in the 'wedge-shaped' valley in either spin state, the spin-polarization at the $E_{\mathrm{F}}$ becomes high. The strong ferromagnetic-type of the B2 structure is CoFe $(P=-0.88)$.

The effects of surrounding potential can control energy level of DOS peak or the band gap. To control the energy
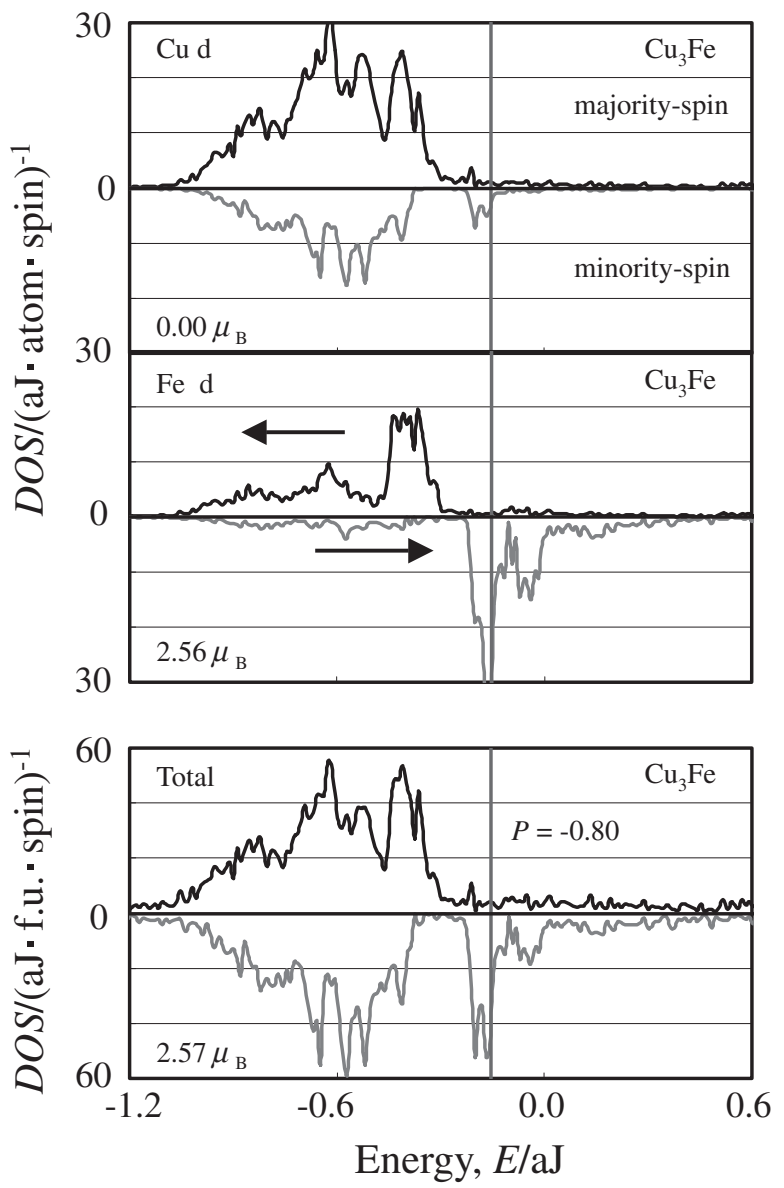

Fig. 10 The local DOS of $\mathrm{Fe}$ and $\mathrm{Cu}$ in $\mathrm{Cu}_{3} \mathrm{Fe}$ (above), and the total DOS of $\mathrm{Cu}_{3} \mathrm{Fe}$ (below). The vertical line shows the $E_{\mathrm{F}}$.

level of DOS peak or the band gap lead us another idea for finding new spintronic materials.

\section{REFERENCES}

1) Y. Tanaka, S. Ishida and S. Asano: Trans. Mater. Res. Soc. Jap. 29 (2004) 3021-3024.

2) S. Ishida, S. Kawakami and S. Asano: Mater. Trans. 45 (2004) 10651069.

3) T. Hahn: International Tables for Crystallography, Vol. A, (D. Reidel, Boston, 1983) pp. 662-664.

4) O. K. Andersen, O. Jepsen and D. Glotzel: Proc. Int. School of Physics 'Enrico Fermi' Course 89, ed. by F. Bassami, F. Fumi and M. P. Tosi, (North-Holland, Amsterdam, 1985) pp. 59-176.

5) V. L. Moruzzi, J. F. Janak and A. R. Williams: Calculated Electronic Properties of Metals, (Pergamon, New York, 1978) pp. 1-22.

6) M. King, W. F. McClune, L. C. Andrews, M. A. Holomany, T. M. Kahmer, B. Lawyer, L. Zwell, B. Post, S. Weissmann, H. F. McMrdie, P. Bayliss and M. E. Mrose: Mineral Powder Diffraction File Databook Sets 1-42, (JCPDS-International Centre for Diffraction Date 1601 Park Lane, Swarthmore, Pennsylvania 19081-2389.U.S.A.) pp. 48.

7) Y. X. Shen, H. R. Gong, L. T. Kong and B. X. Liu: J. Alloys Compd. 366 (2004) 205-212.

8) M. Hansen and K. Anderko: Constitution of Binary Alloys, (McGrawHill, New York, 1958) pp. 543.

9) M. Hansen and K. Anderko: Constitution of Binary Alloys, (McGrawHill, New York, 1958) pp. 681-682. 